\title{
Problemas y conceptos en torno a la caracterización de los regímenes políticos latinoamericanos en el siglo XIX y primeras décadas del XX
}

Javier Moyano*

\section{Resumen}

Nuestro objetivo en este artículo es plantear algunos nudos problemáticos y reflexionar sobre la pertinencia de algunos conceptos, en especial los de régimen oligárquico y régimen notabiliar, para caracterizar a las formaciones políticas latinoamericanas en etapas previas a los procesos que, durante la primera mitad del siglo XX, condujeron en muchos países latinoamericanos a la instauración de ordenamientos políticos más cercanos a la democracia universal, entendida como aquella estructura de gobierno en que la autoridad política se adquiere a través de la lucha competitiva por la conquista del voto popular sin restricciones de ningún tipo. Asimismo, nos interesa considerar la relación entre estas discusiones y dos problemas teóricos clásicos en el análisis político: el del poder y el de la representación.

En función de ese cometido intentaremos esbozar, en primer lugar, un intento de establecimiento de criterios de clasificación de los regímenes políticos durante la etapa en análisis. A continuación plantearemos algunas cuestiones que, desde nuestro punto de vista, son relevantes para analizar el origen, funcionamiento y crisis de tales regímenes. Luego debatiremos sobre los conceptos que pueden ser más apropiados para definirlos. Finalmente, reflexionaremos sobre la relación entre estas discusiones y los problemas del poder y la representación política.

Palabras clave: poder, representación política, régimen oligárquico, régimen notabiliar, América Latina.

\footnotetext{
Abstract:

Our objective in this article is to raise some problematic points and reflect on the relevance of some concepts, especially the oligarchic regime and notabiliar regime, to characterize Latin American political formations process stages before, during the first half of the century XX, in many Latin American countries led to the establishment of

* Doctor por el Colégio de México y Profesor en la Universidad Nacional de Córdoba / Argentina.

Revista Eletrônica da ANPHLAC, n.14, p. 133-156, jan./jun. 2013. http://revista.anphlac.org.br/index.php/revista
} 
political orders closest to universal democracy, understood as the structure of government in which political authority is acquired through competitive struggle for the conquest of the popular vote without restriction of any kind. Also, we want to consider the relationship between these discussions and two classical theoretical issues in political analysis: that of power and representation.

Based on this task will try to outline, first, an attempt to establish criteria for the classification of political regimes during the analysis stage. Then we will raise some issues that, from our point of view are relevant to analyze the origin, operation and crises of such regimes. Then we will discuss the concepts that may be more appropriate to define them. Finally, we will reflect on the relationship between these discussions and issues of power and political representation.

Keywords: power, political representation, oligarchic regime, regime notabiliar, Latin America.

En las últimas décadas, historiadores y científicos políticos han multiplicado sus estudios sobre procesos electorales en América Latina en el largo plazo. Frente a antiguas preocupaciones que, centradas casi exclusivamente en el papel del caudillismo personalista en la política local, muchas veces condujeron a trazar visiones estereotipadas, investigaciones más recientes han puesto énfasis en el desarrollo de las formas electorales y parlamentarias a lo largo de la historia latinoamericana en el último siglo y medio. Aún durante los llamados regímenes oligárquicos o notabiliares del siglo XIX y principios del XX, se observa la necesidad de entender más a fondo la naturaleza del gobierno representativo. Del mismo modo, cobra interés el análisis de la transición desde regímenes políticos en los cuales la participación electoral se veía condicionada por la calificación del voto o por la generalización del fraude y/o la coerción, hacia ordenamientos más cercanos a la democracia universal instaurados durante la primera mitad del siglo XX en muchos países latinoamericanos.

Considerar aportes de estudios sobre historia política en diferentes formaciones históricas, tanto europeas como americanas, ${ }^{1}$ es importante a efectos comparativos para

\footnotetext{
1 Acerca de América Latina, destacan las investigaciones de Antonio Annino, Marcelo Carmagnani y François-Xavier Guerra (ANNINO, 1995; CARMAGNANI, 1993; GUERRA, 1989, 1993 у 2003). También cabe destacar las contribuciones de Fernando Escalante, Alicia Hernández Chaves y el propio Guerra sobre México (ESCALANTE GONZALBO, 1992; GUERRA, 1995; HERNÁNDEZ CHAVEZ, 1993); Edgar Carone, Boris Fausto, Richard Graham, José Murilo de Carvalho y Emilia Viotti da Costa

Revista Eletrônica da ANPHLAC, n.14, p. 133-156, jan./jun. 2013. http://revista.anphlac.org.br/index.php/revista
} 
la comprensión de procesos paralelos, y a la vez diversos, en la historia de los regímenes políticos representativos ${ }^{2}$. En el marco de estas discusiones, mi objetivo en este artículo es plantear algunos nudos problemáticos y reflexionar sobre la pertinencia de algunos conceptos, en especial los de régimen oligárquico y régimen notabiliar, para caracterizar a las formaciones políticas latinoamericanas en etapas previas a los procesos que, durante la primera mitad del siglo $\mathrm{XX}$, condujeron en muchos países latinoamericanos a la instauración de ordenamientos políticos más cercanos a la democracia universal, entendida como aquella estructura de gobierno en que la autoridad política se adquiere a través de la lucha competitiva por la conquista del voto popular sin restricciones de ningún tipo. Asimismo, procuraré considerar la relación entre estas discusiones y dos problemas teóricos clásicos en el análisis político: el del poder y el de la representación.

En función de ese cometido intentaré reflexionar, en primer lugar, en torno a posibles criterios de clasificación de los regímenes políticos durante la etapa en análisis. A continuación plantearé algunas cuestiones que pueden ser relevantes para analizar el origen, funcionamiento y crisis de tales regímenes. Luego efectuaré algunos señalamientos acerca de los conceptos que pueden ser apropiados para definirlos. Finalmente, indagaré sobre la relación entre estas discusiones y los problemas del poder y la representación política.

\section{Los regímenes políticos latinoamericanos en el siglo XIX y primeras décadas del XX. Origen, funciónamiento y crisis}

Como nos indica diversa literatura sobre la problemática en discusión, significativas cuestiones comunes cruzaron los sistemas políticos del siglo XIX y principios del XX en diversos países del mundo occidental ${ }^{3}$. Al respecto, un elemento común de primer orden en los estudios sobre varias naciones ha sido la centralidad ocupada por debates y ensayos relativos a la representación política y al

sobre Brasil (CARONE, 1970; FAUSTO, 1977; GRAHAM, 1990; CARVALHO, 1987, 1995 y 1999 ; VIOTTI DA COSTA, 1995), y de Samuel Valenzuela y Maurice Zeitlin sobre Chile (VALENZUELA, 2000; ZEITLIN, 1984). Respecto a Europa, resultan de interés a los efectos comparativos los estudios de Miguel Artola, Miguel Martínez Cuadrado y José Varela Ortega sobre España (ARTOLA, 1991; MARTÍNEZ CUADRADO, 1991; VARELA ORTEGA, 1977); y de Alain Garrigou, Marcus Kreuzer y Pierre Rosanvallón sobre Francia (GARRIGOU, 1998; KREUZER, 1996; y ROSANVALLÓN, 1999).

2 Tampoco puede ignorarse la influencia ideológica de Europa y Estados Unidos sobre América Latina.

3 Al respecto, revisten interés el análisis teórico efectuado por Dieter Nohlen (NOHLEN, 1997); y los estudios históricos de François Xavier Guerra y Eduardo Posada Carbó (GUERRA, 2003; POSADA CARBÓ, 2000, p. 219).

Revista Eletrônica da ANPHLAC, n.14, p. 133-156, jan./jun. 2013.

http://revista.anphlac.org.br/index.php/revista 
desenvolvimiento de la ciudadanía. Al mismo tiempo, diferencias específicas permiten, a grandes rasgos, ubicar tipos generales distintos, de regímenes políticos, entendidos como el conjunto de instituciones que regulan la lucha por el poder y el ejercicio del mismo, así como los valores sobre los cuales descansan tales instituciones, considerando sobre todo que, por el modo en que condicionan el proceso de formación de la voluntad política y el carácter de la misma, entre tales instituciones revisten significativa importancia la normativa que define quiénes intervienen en la toma de decisiones, y los procedimientos institucionales que garantizan el cumplimiento de tal normativa (LEVI, 1985, pp. 1409-1410; CERRONI, 1992, pp. 140-142). En función de esa definición entendemos, siguiendo a Mauricio Cotta, que un régimen político es representativo cuando las estructuras políticas están sujetas al control de organismos representativos, por lo cual sólo puede hablarse de representación política en sentido estricto cuando hay garantías a la libre emisión del sufragio (COTTA, 1985, pp. 1384$1390)^{4}$.

Cabe distinguir situaciones diversas a partir de las definiciones precedentes. Por ejemplo, Umberto Cerroni esboza, en un trabajo teórico, una tipología de regímenes políticos tomando como criterio de clasificación el problema de la vigencia de la democracia representativa (CERRONI, 1992, pp. 141). En un estudio histórico ya clásico sobre España, Miguel Artola destaca la divergencia que tuvo lugar, en el siglo XIX, entre dos modelos de desarrollo político en función de las posibilidades, dependientes del nivel de transparencia electoral, de que los cambios de opinión incidieran en la composición de las cámaras legislativas (ARTOLA, 1991, pp. 323-324). Pierre Rosanvallon, por su parte, distingue diferentes situaciones históricas según la convergencia o divergencia entre la consagración del derecho a voto y las garantías a su ejercicio (ROSANVALLON, 1999, pp. 412-413). Por otro lado, en el caso de aquellos regímenes políticos caracterizados por la escasa transparencia electoral, Edward Gibson distingue tipos diferentes según el grado de concentración de los recursos que permitían fraguar resultados electorales (GIBSON, 1996, Capítulo I). ${ }^{5}$

Igualmente importante es la literatura sobre semejanzas y diferencias en cuestiones referentes al diseño institucional, tales como los sistemas electorales, la

\footnotetext{
4 La centralidad de esta cuestión en la historia política durante el siglo XIX y principios del XX ha sido destacada por Carlos Malamud, Hilda Sábato y Gonzalo Sánchez Gómez (MALAMUD, 2000, Prólogo; SÁBATO, 1999, Prólogo; SÁNCHEZ GÓMEZ, 1999).

5 Acerca de estas cuestiones, también son sugerentes los aportes de las investigaciones de Aurora Garrido Marín sobre España y Samuel Valenzuela sobre Chile (GARRIDO MARTÍN, 2000, p. 58; VALENZUELA, 2000, p. 148-149).
}

Revista Eletrônica da ANPHLAC, n.14, p. 133-156, jan./jun. 2013. http://revista.anphlac.org.br/index.php/revista 
organización federal o centralista del estado, y las atribuciones de los diferentes poderes -especialmente el ejecutivo y el legislativo- ${ }^{6}$ en el gobierno, pues todas ellas constituyen variables básicas para analizar tanto el funcionamiento del sistema político como las articulaciones entre sociedad y política. El estudio de los sistemas electorales plantea problemas específicos de la operación o instrumentación de la política en un plano fundamental. Para ello diferentes investigadores han considerado que es indispensable analizar en el tiempo los cambios en el diseño de los distritos electorales; el tipo de escrutinio (uninominal o de lista); la representación o no de las minorías y la manera (lista incompleta, representación proporcional) en que ésta se garantiza cuando existe $^{7}$. Tales cuestiones repercuten sobre las relaciones entre fuerzas políticas oficialistas y opositoras, y sobre la dinámica interior de unas y otras ${ }^{8}$.

Por su parte, la organización federal o centralista del estado, así como la existencia o no de herramientas institucionales que favorecen prácticas centralistas en países federales, influye sobre el margen de maniobra de diferentes actores con protagonismo a escala nacional o regional ${ }^{9}$. También es significativo el problema de las atribuciones de los poderes ejecutivo y legislativo, tanto en el orden nacional como en las unidades políticas (provincias, estados, departamentos) que componen un estado. En

\footnotetext{
6 Para analizar el problema del federalismo en América Latina, resultan sumamente relevantes los aportes de Marcello Carmagnani (CARMAGNANI, 1993). Las relaciones entre legislativo y ejecutivo han sido analizadas en diversas investigaciones, como las de Paula Alonso, Natalio Botana, Carlos Malamud, Anne Louise Potter y Peter Smith sobre Argentina (ALONSO, 2000; BOTANA, 1994; MALAMUD, 2000; POTTER, 1979; SMITH, 1974); y Marcello Carmagnani y María Luna Argudín sobre México (CARMAGNANAI, 1994; LUNA ARGUDÍN, 2001). La incidencia de tales variables sobre otros componentes del sistema político ha sido considerada por Karen Remmer en sus investigaciones sobre Argentina (REMMER, 1984, pp. 5-6).

7 Al respecto, son relevantes los trabajos teóricos de Mauice Duverger y Dieter Nohlen (DUVERGER, 1965; NOHLEN, 1997). Asimismo, completos análisis sobre sistemas electorales en diferentes países a fines del siglo XIX y principios del XX, se encuentran presentes en las compilaciones efectuadas por Carlos Malamud y por Sábato y Lettieri (MALAMUD, 1995 y 2000; SÁBATO y LETTIERI, 2003).

8 El influjo de los sistemas electorales sobre las características de los partidos fue analizado por Maurice Duverger (DUVERGER, 1965 y 1988). Sus tesis fueron criticadas, por Klaus Von Beyme y por Giovanni Sartori (VON BEYME, 1989, p. 17; SARTORI, 1988), pero la relación entre sistemas electorales y partidos también es abordada en los trabajos teóricos de Ramón Cotarelo, Víctor Abreu Fernández y Dieter Nolhen (COTARELO, 1996, p. 19; ABREU, 1997; NOHLEN, 1997 capítulos IX y $\mathrm{X})$. Más allá de la pertinencia o no de las hipótesis de Duverger, éstas abrieron el camino para indagar sobre la articulación entre normas electorales y otras componentes del sistema político. Al respecto, Dardé y Estrada, Aurora Garrido Marín, y Ana María Mustapic consideran relaciones de ese tipo en investigaciones sobre regímenes oligárquicos o notabiliares, o bien sobre la transición hacia ordenamientos más cercanos a la democracia universal (DARDÉ y ESTRADA, 1995, pp. 9 y 25-30; GARRIDO MARÍN, 1995, p. 38; MUSTAPIC, 1987, pp. 17-18).

9 Al respecto, la figura jurídica de la intervención federal, sumada a una significativa concentración de recursos en manos de las autoridades nacionales, otorgó, en el caso argentino, relevantes herramientas al gobierno federal para influir sobre la vida política de las provincias. Sobre la combinación entre centralización y descentralización en la organización institucional argentina, es sugerente el análisis de Natalio Botana (BOTANA, 1994, p. 47).
}

Revista Eletrônica da ANPHLAC, n.14, p. 133-156, jan./jun. 2013. http://revista.anphlac.org.br/index.php/revista 
el caso de Argentina, por ejemplo, los atributos institucionales del ejecutivo tanto a nivel federal como provincial, sumados a los recursos informales que presidentes y gobernadores controlaban (BOTANA, 1993, p. 224), constituyen una advertencia a la hora de comparar el papel desempeñado por los legisladores en el caso estudiado con situaciones en que los parlamentos concentraban poderosas facultades ${ }^{10}$.

Además, como ya señalamos, otra diferencia fundamental permite ubicar, a grandes rasgos, dos tipos generales de regímenes políticos durante el período en análisis. Se trata de la distancia entre prescripciones legales -independientemente del grado de amplitud de las mismas respecto a los alcances formales de la ciudadanía- y su cumplimiento en lo atinente a cuestiones electorales. Aunque las líneas de separación en ocasiones son difusas pues, como señala Antonio Annino, disputas y disyuntivas en torno a tales cuestiones fueron comunes a todo el mundo occidental (ANNINO, 1995, pp. 7-8), ${ }^{11}$ esa distancia no constituye sólo una cuestión de grado sino que conduce a distinguir entre regímenes políticos representativos, en los cuales aún la existencia de fraudes parciales no alteraba radicalmente el funcionamiento del conjunto a la hora de reflejar la voluntad ciudadana en la conformación de gobiernos y parlamentos, y otros en los cuales el falseamiento del sistema electoral era decisivo para alcanzar o preservar el poder. Como analizaré más adelante, considero que de las advertencias de Annino no puede deducirse que no sea relevante prestar atención a la distancia entre prescripciones electorales y prácticas políticas, distancia que, sin ser un rasgo exclusivo de América Latina, fue particularmente considerable en diversos países del subcontinente. Como el propio Annino destaca, un conjunto de rasgos específicos -tres siglos gobernados por monarquías católicas, desfase entre la difusión del voto y los procesos de organización del estado y consolidación de élites "nacionales", fragmentación territorial tras la independencia- distinguen a diversas regiones latinoamericanas del resto del mundo atlántico en lo relativo al significado de las reformas que, entre finales del siglo XIX y

\footnotetext{
10 Incluso en Estados Unidos, país de estructura presidencialista, había legislaturas estaduales con amplias facultades. Por ejemplo, en Carolina del Sur durante el siglo XIX, el Congreso local designaba al gobernador y retenía entre sus atribuciones la nominación de los principales cargos en el estado y en los condados. Ello convertía a los legisladores, entre otros motivos por su disposición de recursos clientelares, en actores con mayor margen de maniobra para constituir exitosamente agrupaciones partidarias que en países latinoamericanos. (FORD, 1984 y 1988; HOLT, 1979).

${ }_{11}$ Respecto a esta cuestión, también resultan de utilidad los aportes de José Murilo de Carvalho y de Eduardo Posada Carbó (CARVALHO, 1995, p. 33; POSADA CARBÓ, 2000, p. 219).
}

Revista Eletrônica da ANPHLAC, n.14, p. 133-156, jan./jun. 2013. http://revista.anphlac.org.br/index.php/revista 
principios del XX, contribuyeron a ampliar la participación electoral en la mayor parte de Occidente (ANNINO, 1995, pp. 9-14) ${ }^{12}$.

Entre los ordenamientos políticos en que la manipulación electoral era decisiva a la hora de designar gobiernos y parlamentos, es preciso distinguir a aquellos regímenes en que las posibilidades de cometer fraude y ejercer coerción se encontraban dispersas entre diferentes actores, en ocasiones como consecuencia de la debilidad de las instancias estatales, ${ }^{13}$ de aquellos en que tales recursos tendían a ser monopolizados por el poder ejecutivo. Si se concentra la atención sobre éstos últimos, cabe preguntar cuáles eran las semejanzas y diferencias entre regímenes de este tipo, principalmente latinoamericanos -como el porfiriato mexicano, la primera república brasileña o el ordenamiento argentino anterior a 1912- pero también europeos del sur -como la España de la restauración- respecto al origen, funcionamiento y crisis. Aunque no nos ocuparemos de ello en este artículo, también es preciso comparar situaciones regionales dentro de procesos nacionales.

La cuestión del origen requiere considerar la estabilidad o inestabilidad de las situaciones previas en el corto y mediano plazo. En ese sentido puede distinguirse el caso brasileño de los procesos argentino y mexicano pues hubo fuertes líneas de continuidad entre el imperio y la primera república (CARVALHO, 1995, p. 13). También es relevante considerar el carácter de los pactos -“interpartidarios", interregionales, etc.- que permitieron el establecimiento, consolidación y mantenimiento de tales regímenes. Por ejemplo, Riccardo Forte realiza una sugerente comparación entre los casos mexicano argentino respecto a los pactos en torno a los cuales funcionaban sendos regímenes políticos en las últimas décadas del siglo XIX y primeras del XX (FORTE, 1998). El problema del funcionamiento incluye el análisis del mayor o menor peso de las personalidades, y en esta cuestión el México porfirista (GUERRA, 1995, pp. 74-80) se diferenciaba claramente de los casos argentino y brasileño; la articulación entre política nacional, regional y local; los vínculos entre gobierno y sociedad; las relaciones entre los gobernantes y la oposición; las impugnaciones a tales ordenamientos.

El tratamiento de las crisis de estos regímenes, además de comparar causas, debe poner el acento en el carácter más o menos disruptivo de los desenlaces y, en relación

12 Acerca de las particularidades del mundo hispánico en torno a estas cuestiones, también son relevantes los aportes de Natalio Botana (BOTANA, 1995, pp. 469-478).

13 Como sucedía en los casos de Colombia, Bolivia y Perú (CHIARAMONTI, 1995; IRUROZQUI, 1999 y 2000; POSADA CARBÓ, 1995 y 2000).

Revista Eletrônica da ANPHLAC, n.14, p. 133-156, jan./jun. 2013.

http://revista.anphlac.org.br/index.php/revista 
con ello, en la mayor o menor continuidad entre tales ordenamientos y los regímenes que les sucedieron. Las crisis de los primeros reconocieron denominadores comunes, pues en muchos países se conjugaron, aunque en dosis variables, rupturas y/o debilitamiento de compromisos entre los grupos gobernantes con el desarrollo de una oposición, social y política, más intransigente. La respuesta de los grupos dirigentes ante la creciente impugnación a su predominio, fluctuó entre el refuerzo de la coerción e intentos de adaptación mediante cierta apertura.

No obstante las semejanzas de los procesos, éstos no condujeron a similares desenlaces. En el caso argentino, por ejemplo, segmentos de los propios grupos gobernantes introdujeron, a partir del control de espacios institucionales de decisión, garantías a la transparencia electoral (BOTANA, 1994, pp. 274-275 y 296-297; REMMER, 1984, pp. 90-92; ROCK, 1975, pp. 26-39; SMITH, 1974, pp. 91-93). Esta singularidad, aunque generó significativas transformaciones, impidió que el proceso fuera demasiado disruptivo. En otros casos, el cambio vino por la vía del pronunciamiento, como sucedió en Brasil; o bien, como ocurrió en México, de una revolución que dio lugar a un protagonismo de grupos subalternos sin paralelos en el continente.

Más allá de diferencias en el funcionamiento del sistema político que tuvieron implicancias posteriores, en el caso argentino hubo, en lo relativo a ese carácter escasamente disruptivo de la transición de un régimen a otro, mayores semejanzas con los procesos reformistas de países -como Chile o Uruguay- en que el más o menos generalizado recurso al fraude y la violencia en las prácticas electorales coexistía con la presencia de dos o más fuerzas políticas rivales ocupando espacios institucionales. El caso argentino se ubica en una situación intermedia entre ordenamientos oligárquicos con final disruptivo, y aquellos regímenes "semicompetitivos" en que, como consecuencia de un mayor protagonismo previo de las fuerzas de oposición en ámbitos institucionales, las transformaciones fueron menos abruptas. Aunque no era el caso predominante en América Latina a fines del siglo XIX y principios del XX, la presencia y capacidad de incidencia opositora en espacios institucionales contribuyó a generar escenarios "semicompetitivos" que permitieron, a diferentes actores políticos, desarrollar agrupaciones aceitadas para la disputa electoral y parlamentaria, con identidades más arraigadas en la población y, por todo ello, más susceptibles de adaptación cuando el régimen se encaminara hacia una ampliación de la participación electoral y hacia el establecimiento de recaudos institucionales contra el fraude 
(GIBSON, 1996, Capítulo I; BONILLA SAUS, 1989; CAETANO, 1994 y 1999; DEL CAMPO, 1995; VALENZUELA, 2000; ZUBILLAGA, 1994). En el caso de Chile en la década de 1890, una primera etapa, luego complementada por cambios institucionales que tuvieron lugar a mediados de la década de 1920, en la instauración de mayores garantías a la libre emisión del sufragio fue consecuencia de la labor parlamentaria de la oposición al presidente Balmaceda, si bien el nuevo sistema electoral debió esperar el desenlace de una guerra civil para consolidarse (VALENZUELA, 2000, p. 134). En Uruguay, en tanto, al iniciarse el siglo $\mathrm{XX}$ el propio gobierno procedió a instrumentalizar la expansión efectiva de la ciudadanía con el fin de fortalecer apoyos electorales propios ante la necesidad de garantizar la estabilidad mediante la incorporación al juego electoral de la oposición (BONILLA SAUS, 1989, pp. 129-139). De este modo, en ambos casos se incrementó la capacidad de adaptación de los antiguos grupos gobernantes a los nuevos escenarios.

Planteados algunos problemas relevantes a la hora de analizar los regímenes políticos previos a la instauración de ordenamientos más cercanos a la democracia universal, cabe considerar cuáles conceptos pueden ser pertinentes para definir tales regímenes.

\section{Régimen notabiliar y régimen oligárquico. La pertinencia de los conceptos}

Dos conceptos resultan pertinentes si partimos de la asunción de que, a la hora de definir la naturaleza de un régimen político, el carácter competitivo, semicompetitivo o no competitivo de las elecciones constituye una variable fundamental. Me refiero, en aquellos casos en que destaca la ausencia de procedimientos institucionales que garantizaran el cumplimiento de normativa vigente, relativa al derecho de los ciudadanos a intervenir en la toma de decisiones, a los conceptos de régimen liberalnotabiliar y de régimen democrático representativo con participación limitada. Entendemos como régimen liberal notabiliar un sistema que debe lograr un consenso colectivo con la idea de que la opinión de algunos vale más que su peso numérico (LETTIERI, 2004, p. 203). ${ }^{14} \mathrm{El}$ concepto de régimen democrático representativo con

14 La relación entre sistemas políticos y elecciones competitivas, semicompetitivas y no competitivas ocupa un lugar destacado en el análisis teórico de Dieter Nohlen (NOHLEN, 1997, pp. 12-16). El papel de las élites notabiliares en la génesis de ordenamientos políticos fundados en una normativa liberal en América Latina, ha sido considerado por Riccardo Forte (FORTE, 1998). Los debates en torno al problema de la calidad del elector y de la condición notabiliar de los representantes han sido abordador por Luciano De Privitello (DE PRIVITELLO, 2006, pp. 16- 21). En tanto, Ruggiero Romano y Marcello Carmagnani han reflexionado sobre el carácter notabiliar de la sociedad y la política latinoamericana

Revista Eletrônica da ANPHLAC, n.14, p. 133-156, jan./jun. 2013. http://revista.anphlac.org.br/index.php/revista 
participación limitada, en tanto, ha sido utilizado por Germani por oposición, en el caso argentino, al régimen instaurado con la reforma electoral de 1912, al cual define como democracia representativa con participación ampliada (GERMANI, 1977, p. 304).

Ahora bien, si en un régimen no competitivo el acceso a recursos de poder, en gran medida para garantizar la manipulación electoral, se encuentra altamente concentrada en una minoría gobernante aunque esta no constituya un grupo absolutamente monolítico ni omnipotente, el calificativo de oligárquico resulta operativo para dar cuenta, dados los mecanismos usados por esa minoría para preservar el poder, de un aspecto distintivo de ese tipo de régimen. Cabe señalar, siguiendo a Ansaldi, que el uso escogido del concepto de oligarquía no hace referencia a una clase social, sino a un tipo de régimen (ANSALDI, 1992, pp. 45-47). Este tipo de régimen se caracteriza por el hecho de que el control no era ejercido por los ciudadanos sobre los gobernantes sino a la inversa ya que, aunque la designación de candidatos era resultado de complejas negociaciones dentro del grupo que ocupaba el gobierno, los comicios se trastocaron en "designación”, mediante fraude y coerción, de las nuevas autoridades por sus antecesores, convertidos de ese modo en "gobiernos electores" (ANSALDI, 1992, pp. 45-47; BOBBIO, 1985, p. 1118; y BOTANA, 1994, pp. 69-78, 175 y 312).

Cabe señalar que ese énfasis en el término oligárquico puede ser objeto de cuestionamientos. Ello se debe a que implica poner el acento en la "fabricación" de comicios como medio de preservar el poder $\mathrm{y}$, por lo tanto, en la existencia de restricciones al ejercicio de derechos ciudadanos que en algunos casos eran reconocidos por la legislación decimonónica. Si bien existe un consenso en la historiografía respecto a la presencia más o menos generalizada del fraude y la coerción antes de los procesos reformistas de principios del siglo XX en diversos países del mundo atlántico, el énfasis sobre la cuestión de la manipulación electoral y la caracterización de los regímenes decimonónicos como restrictivos de la participación han recibido objeciones en etapas recientes, en especial a partir de las reflexiones de Antonio Annino, quien sugiere que la atención de las investigaciones debe orientarse, más que hacia el resultado de los comicios y su peso en las contiendas políticas, hacia las prácticas y valores que

desde el primer tercio del siglo XIX (ROMANO y CARMAGNANI, 1999, pp. 380-387). Juan Cáceres Muños ha analizado el modo en que una sociedad notabiliar definió modelos políticos en América Latina (CÁCERES MUÑOZ, 2010, p. 63). La interacción, en el caso mexicano, entre pensamiento liberal y mantenimiento de una sociedad notabiliar, ha sido considerada por Marcello Carmagnani (CARMAGNANI, p. 62).

Revista Eletrônica da ANPHLAC, n.14, p. 133-156, jan./jun. 2013. http://revista.anphlac.org.br/index.php/revista 
definieron la incorporación de votantes al mundo de la representación moderna $\left(\right.$ ANNINO, 1995, p. 8) ${ }^{15}$.

Otras propuestas, entre las que destaca la de Hilda Sábato, reconocen la existencia de restricciones a la participación electoral, pero ubican el énfasis principal del análisis en torno a los canales a través de los cuales, incluso en el marco de tales condicionamientos, la sociedad interpelaba a los gobernantes (SÁBATO, 1998, p. $175)^{16}$. Roy Hora destaca, en un estudio sobre la provincia argentina de Buenos Aires, la relevancia, en la historiografía más reciente sobre la política decimonónica, de prestar atención a problemas que no se explican sólo por la construcción y características de un orden oligárquico, y, sin desconocer su carácter fraudulento, alerta contra las visiones que lo ubican como un orden inalterable antes de su crisis final (HORA, 2001, p. 2). Paula Alonso, por su parte, considera que, dado que hubo comicios medianamente competitivos en la ciudad y en la provincia de Buenos Aires en la década de 1890, en el caso argentino el cambio que supuso la reforma electoral de 1912 no fue demasiado abrupto (ALONSO, 2000, pp. 211-230). En un lúcido ensayo, Elías Palti cuestiona, por anacrónico y teleológico, el uso del concepto de "república verdadera" como presunto modelo democrático a alcanzar por los sistemas políticos decimonónicos (PALTI). Una sistematización de las críticas al uso del adjetivo de restrictivo para caracterizar a regímenes políticos como el estudiado puede encontrarse en el análisis de Alberto Lettieri, quien sostiene que, en tales regímenes, la legitimidad no dependía del sufragio, cuya función no era representar a la sociedad; que era creciente la inclusión por la progresiva ampliación de la base electoral; y que tras el calificativo de restrictivo subyace una interpretación finalista acerca del deber ser de un régimen político (LETTIERI, 2004, pp. 185-207).

Tales críticas abren un campo de análisis ausente en muchos trabajos que sólo enfocan su mirada hacia el problema de la manipulación electoral, pero no necesariamente están cuestionando la ubicación de la distancia entre prescripciones y prácticas como criterio de clasificación de los regímenes políticos de fines del siglo XIX y principios del XX. Por un lado, si el foco de una investigación sobre historia política se orienta, entre otras opciones posibles, hacia la cuestión del poder, la existencia de

15 Entre otros, sugerentes análisis en una dirección más o menos semejante se encuentran en los estudios de González Bernaldo (1999) sobre la ciudad de Buenos Aires a mediados del siglo XIX; y de Irurozqui (2000, p. 264) sobre Bolivia. Acerca de estas cuestiones, véase también Malamud (2000, p. 10).

16 Hilda Sábato se refiere al régimen político argentino anterior a 1880 como un sistema con sufragio universal, voto restringido, participación ampliada y prácticamente sin ciudadanía política (SÁBATO, 1998, p. 175). Sobre estas cuestiones véase también el análisis de Inés Rojkind (2009).

Revista Eletrônica da ANPHLAC, n.14, p. 133-156, jan./jun. 2013. http://revista.anphlac.org.br/index.php/revista 
mayores o menores garantías a la democracia es una variable fundamental para estudiar los escenarios en que se desarrollan disputas y negociaciones entre los actores. Por otro lado, como indica Pierre Rosanvallón, la libertad de elección del ciudadano queda garantizada sólo cuando las técnicas electorales impiden el fraude (ROSANVALLÓN, 1999, pp. 411-418). En el señalamiento de Rosanvallón acerca de que, en el caso francés, la democracia triunfó pronto como "religión" pero como régimen se impuso tardíamente, siendo la culminación de ese proceso la instauración de la casilla como garantía del secreto del sufragio (ROSANVALLÓN, 1999, pp. 411-418), es posible apreciar que la tecnología electoral es un elemento constitutivo de un régimen político. En la misma dirección se orienta el análisis de Mauricio Cotta, quien define representación política como "sistema institucionalizado de responsabilidad política, realizado a través de la designación electoral libre de ciertos organismos fundamentales”, y destaca que la dimensión del procedimiento es sustancial para analizar relaciones entre electos y electores, pues no pueden dejar de considerarse las posibilidades y límites de los mecanismos institucionales que garantizan el cumplimiento de las prescripciones legales (COTTA, 1985, pp. 1387-1390). Umberto Cerroni, por su parte, afirma que sólo puede hablarse de consenso cuando hay instituciones capaces de garantizarlo, expresarlo, medirlo y revocarlo (CERRONI, 1992, p. 115). En el marco de estas conceptualizaciones, cabe destacar el aserto de Rosanvallon respecto a la separación que, en Francia y América Latina, se produjo entre la "historia política" y la "historia técnica" del sufragio universal (ROSANVALLÓN, 1999, p. 411-418).

Contribuye a un tratamiento de los problemas planteados reconocer los aportes de diversos investigadores que han permitido matizar el contraste entre la política decimonónica y etapas más recientes, en especial a partir del desarrollo de la hipótesis de que las prácticas electorales, anteriores a las reformas que garantizaron mayor transparencia, apuntalaron procesos de construcción de la ciudadanía. Ahora bien, desde una perspectiva que, con intenciones clasificatorias que pretenden no ser finalistas pero no pueden evitar ser retrospectivas, es difícil desconocer que, en diversos casos latinoamericanos, una más plena integración de muchos actores al sistema político recién tuvo lugar luego de que diversas reformas legales garantizaron una mayor transparencia en la competencia electoral. En otro orden, aunque es relevante analizar como se generan, en regímenes sin comicios competitivos, mecanismos que los hacen permeables a presiones de la sociedad, y si bien reviste interés considerar cómo en tales

Revista Eletrônica da ANPHLAC, n.14, p. 133-156, jan./jun. 2013. http://revista.anphlac.org.br/index.php/revista 
regímenes los gobernantes alcanzan legitimidad y aceptación entre el público, es necesario precisar que, al tratarse de bases precarias no garantizadas por mecanismos institucionalizados, en tales casos sólo es posible hablar de fenómenos representativos con algunas analogías respecto a la representación política en sentido estricto (COTTA, 1985, pp. 1387-1390).

En cuanto a los señalamientos de Paula Alonso, considero que aún cuando, en un determinado país, tengan lugar comicios competitivos en algunos distritos, ello puede no ser suficiente para contrarrestar los efectos, en lo relativo a la preservación del control de los principales resortes del poder por parte de una minoría gobernante, de la manipulación electoral en la mayor parte del territorio. Respecto a las objeciones sintetizadas por Lettieri, considero pertinente destacar que el carácter restrictivo de un determinado ordenamiento político no depende, necesariamente, de cuáles sean los fundamentos de su legitimidad. Por otro lado, hablar de inclusión progresiva hace referencia a preexistentes exclusiones, aun cuando sea preciso reconocer que tal contraste es efectuado a partir de una visión retrospectiva del proceso. Asimismo, considero que, más allá de cualquier juicio sobre el deber ser de un régimen político, antes de los procesos reformistas que, a principios del siglo $\mathrm{XX}$, garantizaron en diferentes países una mayor transparencia electoral, diversos factores limitaban la libre emisión del sufragio que la propia legislación existente consagraba como un derecho en muchos países del continente.

\section{Los problemas del poder y la representación ciudadana en las discusiones sobre el régimen político}

Por su capacidad de inclusión de otros asuntos y, en consecuencia, por sus más amplios alcances explicativos, entre otras entradas posibles el énfasis principal en el estudio de los ordenamientos políticos decimonónicos puede orientarse, de modo alternativo o complementario, hacia dos problemas clásicos en el análisis político, ambos relacionados con la cuestión de la toma de decisiones, cuestión decisiva a la hora de caracterizar la naturaleza de un régimen político. Se trata, en primer lugar, del problema del poder como relación asimétrica entre dos o más actores, lo cual influye en el proceso de imposición de decisiones de unos sobre otros. En segundo lugar, del problema de la representación ciudadana, mirada centrada, como señala Umberto Cerroni, en los mecanismos de mediación entre demandas de la sociedad civil e instancias a cargo de tomar decisiones políticas (CERRONI 1992, p. 173-174).

Revista Eletrônica da ANPHLAC, n.14, p. 133-156, jan./jun. 2013. http://revista.anphlac.org.br/index.php/revista 
La cuestión del poder, entendido por la sociología weberiana como la probabilidad de imponer la propia voluntad al comportamiento ajeno (WEBER, 1944, p. 53; BENDIX, 1960, p. 277), incluye, como señala Lukes, tres dimensiones. En primer lugar, la dimensión del control para garantizar acatamiento. En segundo lugar, la dimensión de la dependencia en función de la cual un actor consigue que otro se pliegue a su voluntad o a sus intereses. Por último, la dimensión de la desigualdad en la capacidad para procurarse ventajas o recursos valorados pero escasos (LUKES, 1988, pp. 721-723).

El análisis de la representación política, en tanto, requiere distinguir entre la historia de un concepto que fungió como legitimador de acciones de diferente carácter, y la génesis de un sistema fundado en determinados mecanismos y canales mediadores entre estado y sociedad. Este problema, en la doble dimensión señalada, se inserta en la red institucional de un sistema político en tanto cuestión condicionada y condicionante al mismo tiempo. Cuestión condicionada, pues puede ser explicada mediante un conjunto de variables, como las garantías al ejercicio de derechos civiles, la presencia o no de élites políticas alternativas y de posibilidades de recambio en el gobierno, y las características de la cultura política. Cuestión condicionante, dado que la eficacia, legitimidad y características del sistema representativo repercuten en el funcionamiento del sistema político. (CERRONI, 1992, p. 137; COTTA, 1985, pp. 1387-1389; MALAMUD, 1995, pp. 5-6)

La consideración del problema de la representación implica tener en cuenta quiénes eligen -lo cual incluye, a su vez, el reconocimiento del derecho al voto y las garantías a su ejercicio- y quiénes son electos; el tipo de control e influencia que sobre éstos últimos ejercen los gobernados; y los mecanismos de articulación entre intereses sociales particulares y decisiones políticas obligatorias para todos, lo cual comprende también aquellas maneras en que, cuando no había garantías para la competencia electoral, se abrían canales para la participación ciudadana.

El análisis de procesos conducentes a la instauración de regímenes representativos comprende múltiples dimensiones, pues se trata de cuestiones en interacción con el contexto social y con problemas relativos al orden y al poder. Es preciso tener en cuenta condiciones favorables o limitantes, como la capacidad del estado para imponer una normativa uniforme; o las posibilidades de la sociedad de protegerse contra la aplicación discrecional de tal normativa. También es necesario estudiar a los actores -identidades, prácticas, etc.- que promovían o resistían cambios en 
lo relativo a la representación, o bien buscaban adaptarse, moderando o potenciando sus efectos, a transformaciones o continuidades en esa materia. Otro asunto de interés es, como ya señalamos en otro apartado, el carácter gradual o disruptivo de los procesos, dado el influjo posterior -sustitución o no de las élites, pervivencia de formas institucionales anteriores, mayor o menor legitimidad de los canales de cambiogeneralmente ejercido por la manera en que las transformaciones se producían.

Cabe preguntar sobre la posibilidad y pertinencia de intentar articular el análisis del poder con el análisis de la representación en los estudios sobre regímenes notabiliares u oligárquicos. En ese sentido, poner énfasis en la problemática del poder es provechoso para analizar la desigual capacidad de juego de diferentes actores, potenciada por las características distintivas del régimen político. Ante las críticas a los enfoques centrados en el poder como relación asimétrica, cabe recordar el aserto de Charles Wright Mills acerca de que “...no hay nada en la naturaleza de la historia que excluya la función central de pequeños grupos de personalidades decisivas" (MILLS, 1963, p. 33). Sin embargo, un análisis centrado exclusivamente en el problema del poder adolece de limitaciones a la hora de considerar mecanismos a través de los cuales actores ajenos a las élites participan en las decisiones, si bien, como señala Panebianco, el poder sólo puede ejercerse satisfaciendo expectativas de quienes resultan desfavorecidos en las relaciones de poder (PANEBIANCO, 1990, p. 64).

Poner énfasis, en cambio, en la cuestión de la representación, subsana tales deficiencias, pero sus aportes no resultan suficientemente convincentes cuando el interés de una investigación se orienta hacia aquellos recursos informales negados en el discurso público pero con incidencia sobre las decisiones, especialmente en aquellas situaciones históricas en que una considerable distancia entre mecanismos institucionales reconocidos como legítimos y prácticas predominantes es funcional a intereses de actores dotados de mayor margen de maniobra. Si bien, en ocasiones, en los análisis sobre representación política se reconoce que el peso de prácticas informales puede limitar la eficacia de las instituciones representativas, no siempre se prioriza la preocupación por las causas de esa incidencia ni por la manera en que tales prácticas operan.

Más allá de cuestionamientos con pretensión de descalificar, ${ }^{17}$ la operatividad de una perspectiva centrada en el problema del poder o en la cuestión de la representación

17 Como los formulados por Umberto Cerroni a las investigaciones centradas en el problema del poder (CERRONI, 1992, pp. 173-174), aunque sus argumentos se limitan a poner en evidencia exageraciones en

Revista Eletrônica da ANPHLAC, n.14, p. 133-156, jan./jun. 2013.

http://revista.anphlac.org.br/index.php/revista 
en el análisis de regímenes oligárquicos o notabiliares, depende del tipo de problemas específicos que al investigador le interese estudiar. Cabe hacer notar que, en un período en que la cuestión de los canales de articulación entre sociedad civil y decisión política ocupaba el centro de las discusiones entre diversos actores que, precisamente, disputaban espacios de poder, sugerentes propuestas, como la de Hilda Sábato, plantean la necesidad de integrar problemas relativos al poder y a las formas de mediación entre sociedad y política (SÁBATO, 1999, Introducción ). En similar dirección se orientan diversos trabajos sobre historia política de fines del siglo XIX y principios del XX en diferentes países. Por ejemplo, Carlos Dardé y Manuel Estrada afirman que el análisis de problemas de representación política puede ser complementario de estudios como el del caciquismo en el cometido de explicar realidades electorales (DARDE y ESTRADA, 1995, p. 12). François-Xavier Guerra, siempre preocupado por el problema de la representación, asigna importancia a las "relaciones de poder real" (GUERRA 1995, p. 22). Carlos Malamud vincula ambas cuestiones cuando destaca la preocupación de muchos dirigentes por instaurar sistemas electorales transparentes sin descuidar la preservación de espacios de poder bajo su control (MALAMUD 2000, pp. 10-12). Gonzalo Sánchez Gómez discute alrededor de esa misma relación cuando sostiene que las instancias de intermediación entre sociedad civil y estado eran actos de poder más que de representación (SÁNCHEZ GÓMEZ 1999, p. 439).

\section{A modo de cierre}

La historiografía más o menos reciente sobre el siglo XIX y primeras décadas del XX en América Latina, ha abierto diversos caminos, conducentes a matizar antiguas generalizaciones y estereotipos, a visualizar múltiples dimensiones en el análisis, y a tomar precauciones contra el peligro de caer en anacronismos fundados en visiones finalistas de la historia. Cabe preguntar si estos aportes implican el destierro definitivo de algunas preocupaciones clásicas, entre las que destaca el interrogante acerca de los efectos de la manipulación electoral sobre las estructuras de poder, o bien pueden contribuir, sin que ello agote sus potencialidades, a enriquecer las indagaciones en torno a aquellas preocupaciones. Los interrogantes en torno a cuáles son los umbrales que, en

que incurren algunas de ellas. Sin el mismo tono descalificador, también Fernando Escalante critica, desde otra perspectiva, el énfasis que muchos estudios políticos ponen sobre la cuestión del poder y propone, como alternativa, orientar la atención hacia el problema del orden (ESCALANTE GONZALBO, 1995, pp. 43-48). Sobre las relaciones entre poder y orden en diferentes tradiciones intelectuales, también son altamente sugerentes los análisis de MichelÁngelo Bovero y Antonio Passano (BOVERO, 1984, pp. 38-43; PASSANO, 1991, pp. 11-33).

Revista Eletrônica da ANPHLAC, n.14, p. 133-156, jan./jun. 2013. http://revista.anphlac.org.br/index.php/revista 
lo relativo a los procedimientos de toma de decisiones y a los actores influyentes, definen la naturaleza de un régimen político; la opción por la utilización del concepto de régimen oligárquico para caracterizar a muchos ordenamientos políticos latinoamericanos; y la ubicación del problema del poder como una de las principales preocupaciones a la hora de estudiar la política en el continente durante la etapa en cuestión, constituyen un conjunto de alternativas que, aunque posiblemente cuestionables desde diferentes lugares y posiciones, pueden contribuir al aprovechamiento de nuevos aportes y perspectivas sin abandonar preocupaciones clásicas que, desde mi punto de vista, no han perdido aun su relevancia.

\section{Referencias bibliográficas:}

ABREU FERNANDEZ, Victor. Sistemas de partidos y sistemas electorales. En: Curso de Partidos Políticos. Madrid: Akal Universitaria, 1997, p. 229-261.

ALONSO, Paula. Entre la revolución y las urnas. Los orígenes de la Unión Cívica Radical y la política argentina en los años '90. Buenos Aires: Editorial Sudamericana, Universidad de San Andrés, 2000.

ANNINO, Antonio (coordinador). Historia de las elecciones iberoamericanas, siglo XIX. Buenos Aires: Fondo de Cultura Económica, 1995.

ANSALDI, Waldo. Frívola y casquivana, mano de hierro en guante de seda. Una propuesta para conceptualizar el término oligarquía en América Latina. Cuadernos de CLAEH, Montevideo, n. 61, pp. 43-48, 1992.

ARTOLA, Miguel. Partidos y programas políticos, 1808-1936. I. Los partidos políticos. Madrid: Alianza Editorial, 1991.

BENDIX, Reihhard. Max Weber. Buenos Aires: Amorrortu, 1960.

BOBBIO, Norberto. Oligarquía. En: BOBBIO, Norberto; MATEUCCI, Nicola. Diccionario de política. México: Siglo XXI Editores, 1985, p. 1118-1122.

BONILLA SAUS, Javier. Partidos políticos y formación del Estado en Uruguay. Cuadernos de CLAEH, n. 50, pp. 113-139, 1989.

BOTANA, Natalio. Comentarios finales. En: ANNINO, Antonio (coordinador). Historia de las elecciones iberoamericanas, siglo XIX. Buenos Aires: Fondo de Cultura Económica, 1995, p. 469-479.

BOTANA, Natalio. El federalismo liberal en Argentina: 1852-1930. En: CARMAGNANI, Marcello (coordinador) Federalismos latinoamericanos: México/ 
Brasil/ Argentina. México: El Colegio de México, Fideicomiso Historia de las Américas, Fondo de Cultura Económica, 1993, p. 224-259.

BOTANA, Natalio. El orden conservador. La política argentina entre 1880 y 1916. Buenos Aires: Sudamericana, 1994.

BOVERO, Michelángelo. Lugares clásicos y perspectivas contemporáneas sobre política y poder. En: BOBBIO, Norberto; BOVERO, Michelángelo. Origen y fundamentos del poder político. México: Enlace-Grijalbo, 1984, pp. 37-64.

CACERES MUÑOZ, Juan. Apuntes para una historia de las elecciones en América Latina. Continuidad y cambios, 1750-1850. Espacio Regional, Osorno, v. 2, n. 7, pp. 55-67, julio-diciembre 2010.

CAETANO, Gerardo. Ciudadanía política e integración social en el Uruguay (19001933). En: SÁBATO, Hilda. (coordinadora). Ciudadanía política y formación de las naciones. Perspectivas históricas de América Latina. México: El Colegio de México, Fideicomiso Historia de las Américas, Fondo de Cultura Económica, 1999, pp. 405-427. CAETANO, Gerardo. La articulación del sistema político uruguayo (1919-1933). En: DEVOTO, Fernando; FERRARI, Marcela. La construcción de las democracias rioplatenses: proyectos institucionales y prácticas políticas. 1900-1930. Buenos Aires: Biblos, Universidad Nacional de Mar del Plata, 1994, pp. 69-104.

CARMAGNANI, Marcello. Estado y mercado. La economía pública del liberalismo mexicano, 1850-1911. México: Fondo de Cultura Económica, El Colegio de México, 1994.

CARMAGNANI, Marcello (coordinador). Federalismos latinoamericanos: México/ Brasil/ Argentina. México: El Colegio de México, Fideicomiso Historia de las Américas, Fondo de Cultura Económica, 1993.

CARMAGNANI, Marcello. La libertad, el poder y el estado en la segunda mitad del siglo XIX. Disponible en www.estudioshistoricos.inah.gov.mx/.../wp.../historias_15_5564.pdf

CARONE, Edgar. A República Velha (institucoes e classes sociais). São Paulo: Difusão Europeia del Livro, 1970.

CARVAlHO, José Murilo de. Desenvolvimiento de la ciudadanía en Brasil. México:

El Colegio de México, Fideicomiso Historia de las Américas, Fondo de Cultura Económica, 1995.

CARVALHO, José Murilo. Dimensiones de la ciudadanía en el Brasil del siglo XIX. En: SÁBATO, Hilda (coordinadora). Ciudadanía política y formación de las naciones. 
Perspectivas históricas de América Latina. México: El Colegio de México, Fideicomiso Historia de las Américas, Fondo de Cultura Económica, 1999, pp. 321-344.

CARVALHO, José Murilo. Teatro de sombras. A política imperial. Rio de Janeiro: Edições Vértice e Impeij, 1987.

CERRONI, Umberto. Política. Método, teorías, procesos, sujetos, instituciones y categorías. México: Siglo XXI Editores, 1992.

CHIARAMONTI, Gabriella. Andes o nación: la reforma electoral de 1896 en Perú. En: ANNINO, Antonio (coordinador). Historia de las elecciones iberoamericanas, siglo XIX. Buenos Aires: Fondo de Cultura Económica, 1995, pp. 315-346.

COTARELO, Ramón. Los Partidos Políticos. Madrid: Editorial Sistema, 1996.

COTTA, Mauricio. Representación política. En: BOBBIO, Norberto; MATEUCCI, Nicola. Diccionario de política. México: Siglo XXI Editores, 1985, pp. 1384-1390.

DARDE, Carlos. Avanzar retrocediendo. La reforma electoral española de 1878. En: MALAMUD, Carlos (coordinador). Legitimidad, representación y alternancia en España y América Latina: las reformas electorales (1880-1930). México: El Colegio de México, Fideicomiso Historia de las Américas, Fondo de Cultura Económica, 2000, pp. $19-40$.

DARDÉ, Carlos; ESTRADA, Manuel. La representación social y territorial en la legislación electoral española, 1808-1874. En: MALAMUD, Carlos (editor). Partidos políticos y elecciones en América Latina y la Península Ibérica, 1850-1930. Madrid: Instituto Universitario Ortega y Gasset, 1995, pp. 9-32.

DE PRIVITELLO, Luciano, Representación política, orden y progreso. La reforma electoral de 1902. Política y Gestión, UNSAM, v. 9, Año 2006.

DEL CAMPO, Esther. Los partidos políticos y la política en Argentina y Chile, 18801930. En: MALAMUD, Carlos (editor). Partidos políticos y elecciones en América Latina y la Península Ibérica, 1850-1930. Madrid: Instituto Universitario Ortega y Gasset, 1995, Vol. II, pp. 41-64.

DUVERGER, Maurice. La ley de Duverger: cuarenta años después. En: DUVERGER, Maurice; SARTORI, Giovanni. Los sistemas electorales. San José de Costa Rica: CAPEL, 1988, pp. 9-35.

DUVERGER, Maurice. Los partidos políticos. México: Fondo de Cultura Económica, 1965.

ESCALANTE GONZALBO, Fernando. Ciudadanos imaginarios. México: El Colegio de México, 1992.

Revista Eletrônica da ANPHLAC, n.14, p. 133-156, jan./jun. 2013.

http://revista.anphlac.org.br/index.php/revista 
FAUSTO, Boris (direção). Historia Geral da Civilizacao Brasileira. III Brasil republicano. 1- Estructura de poder e economía. (1989-1930). São Paulo (Brasil): Difel, 1977.

FORD, Lacy K. Jr. Origins of Southern Radicalism. The South Carolina Upcountry, 1800-1860. New York, Oxford: Oxford University Press, 1988.

FORD, Lacy K. Jr. Rednecks and Merchants: Economic Development and Social Tensions in the South Carolina Upcountry, 1865-1900. The journal of American History, Bloomington, Indiana, v. 71, n. 2, September, p. 294-318, 1984.

FORTE, Riccardo. El Sistema Electoral como mecanismo de hegemonía política. Metapolitica. Ed. CEPCOM. V. 2, 1998. Disponible en www.hechohistorico.com.ar/Trabajos/Valores.../lecvmx041.html

GARRIDO MARIN, Aurora. Electores y distritos electorales en España, 1874-1936 En: MALAMUD, Calos (editor). Partidos políticos y elecciones en América Latina y la Península Ibérica, 1850-1930. Vol. I. Madrid: Instituto Universitario Ortega y Gasset, 1995, pp. 33-54.

GARRIDO MARÍN, Aurora. La reforma electoral de 1890. En: MALAMUD, Carlos (coordinador). Legitimidad, representación y alternancia en España y América Latina: las reformas electorales (1880-1930). México: El Colegio de México, Fideicomiso Historia de las Américas, Fondo de Cultura Económica, 2000, pp. 41-61.

GARRIGOU, Alain. Il voto in Francia durante la Terza Republica. Quaderni Storici, Il Mulino, 97, anno XXXIII, n. 1, aprile, pp. 31-58, 1998.

GERMANI, Gino. Política y sociedad en una época de transición. De la sociedad tradicional a la sociedad de masas. Buenos Aires: Paidós, 1977.

GIBSON, Edward. Class and Conservative Parties. Argentina in Comparative Perspective. Baltimore and London: The Johns Hopkins University Press, 1996.

GONZALEZ BERNALDO, Pilar. Los clubes electorales durante la secesión del Estado de Buenos Aires (1852-1861): La articulación de dos lógicas de representación política en el seno de la esfera pública porteña. En: SÁBATO, Hilda (coordinadora). Ciudadanía política y formación de las naciones. Perspectivas históricas de América Latina. México: El Colegio de México, Fideicomiso Historia de las Américas, Fondo de Cultura Económica, 1999, pp. 142-161.

GRAHAM, Richard. Patronage ad Politics in Nineteenth Century. Brasil. Stanford, California: Stanford University Press, 1990. 
GUERRA, François-Xavier. De la política antigua a la política moderna: algunas proposiciones. Anuario IEHS, Tandil, n.18, pp. 201-212, 2003.

GUERRA, François-Xavier. Hacia una nueva historia política. Actores sociales y actores políticos. Anuario IEHS, Tandil, IV, p. 243-264, 1989.

GUERRA, François-Xavier. La metamorfosis de la representación en el siglo XIX, En: COUFFIGNAL, Georges (comp.) Democracias posibles. El desafío latinoamericano. Buenos Aires: Fondo de Cultura Económica, 1993, p. 39-68.

GUERRA, François-Xavier. México: del Antiguo Régimen a la Revolución. Tomo I. México: Fondo de Cultura Económica, 1995.

HERNANDEZ CHAVES, Alicia. La tradición republicana del buen gobierno. México: El Colegio de México, Fideicomiso Historia de las Américas, Fondo de Cultura Económica, 1993.

HOLT, Thomas. Black over White. Negro Political Leadership in South Carolina during Reconstruction. Urbana and Chicago: University of Illinois Press, 1979.

HORA, Roy. Autonomistas, Radicales y Mitristas: el orden oligárquico en la provincia de Buenos Aires (1880-1912). Boletín del Instituto de Historia Argentina y Americana Dr. Emilio Ravignani, Buenos Aires, III, n. 23, 2001.

IRUROZQUI, Marta. ¡Que vienen los mazorqueros! Usos y abusos discursivos de la corrupción y la violencia en las elecciones bolivianas, 1884-1925, En: SÁBATO, Hilda (coordinadora). Ciudadanía política y formación de las naciones. Perspectivas históricas de América Latina. México: El Colegio de México, Fideicomiso Historia de las Américas, Fondo de Cultura Económica, 1999, pp. 295-317.

IRUROZQUI, Marta. Sobre leyes y transgresiones: reformas electorales en Bolivia, 1826-1952. En: MALAMUD, Carlos (coordinador). Legitimidad, representación y alternancia en España y América Latina: las reformas electorales (1880-1930). México: El Colegio de México, Fideicomiso Historia de las Américas, Fondo de Cultura Económica, 2000, pp. 262-291.

KREUZER, Marcus. Democratization and Changing Methods of Electoral Corruption in France from 1815 to 1914. En: LITTLE, Walter y POSADA CARBÓ, Eduardo. Political Corruption in Europe and Latin America. New York: St. Martin’s, 1996, pp. 97-112.

LETTIERI, Alberto. Seis lecciones de política. Buenos Aires: Prometeo, 2004.

LEVI, Lucio. Régimen Político. En: BOBBIO, Norberto; MATEUCCI, Nicola. Diccionario de política. México: Siglo XXI Editores, 1985, p. 1409-1414.

Revista Eletrônica da ANPHLAC, n.14, p. 133-156, jan./jun. 2013. http://revista.anphlac.org.br/index.php/revista 
LUKES, Steven. Poder y autoridad. En: BOTTOMORE, Tom.; NISBET, Robert. (compiladores). Historia del análisis sociológico. Buenos Aires: Amorrortu editores, 1988, pp. 718-767.

LUNA ARGUDIN, María Leonila. El Congreso de la Unión y las transformaciones del liberalismo y federalismo mexicanos, 1857-1910. Tesis para optar al grado de Doctor en Historia, El Colegio de México, 2001.

MALAMUD, Carlos. La efímera reforma electoral de 1902 en Argentina. En: MALAMUD, Carlos (coordinador). Legitimidad, representación y alternancia en España y América Latina: las reformas electorales (1880-1930). México: El Colegio de México, Fideicomiso Historia de las Américas, Fondo de Cultura Económica, 2000, pp. 103-129.

MALAMUD, Carlos (editor). Partidos políticos y elecciones en América Latina y la Península Ibérica, 1850-1930. Madrid: Instituto Universitario Ortega y Gasset, 1995.

MARTINEZ CUADRADO, Miguel. Restauración y crisis de la monarquía (18741931). Madrid: Alianza Editorial, 1991.

MILLS, Charles Wrigth. La élite del poder. México-Buenos Aires: Fondo de Cultura Económica, 1963.

MUSTAPIC, Ana María. El Partido Conservador de la Provincia de Buenos Aires ante la intervención federal y la competencia democrática: 1917-1928. Buenos Aires: Instituto Torcuato Di Tella, 1987.

NOHLEN, Dieter. Sistemas electorales y partidos políticos. México: Fondo de Cultura Económica, 1997.

PALTI, Elías. ¿De la República posible a la República verdadera? Oscuridad y transparencia de los modelos políticos. Disponible en historiapolitica.com/datos/biblioteca/palti/pdf

PANEBIANCO, Angelo. Modelos de partido. Madrid: Alianza 1990.

PASSANO, Antonio (Introducción y selección de textos). Sociología del poder. Buenos Aires: Centro Editor de América Latina, 1991.

POSADA CARBO, Eduardo. Civilizar las urnas: conflicto y control en las elecciones colombianas, 1830-1930 En: MALAMUD, Carlos (editor). Partidos políticos y elecciones en América Latina y la Península Ibérica, 1850-1930, Vol. I. Madrid: Instituto Universitario Ortega y Gasset, 1995, pp. 145-166.

POSADA CARBO, Eduardo. Fraude al sufragio: la reforma electoral en Colombia, 1830-1930. En MALAMUD, Carlos (coordinador). Legitimidad, representación y 
alternancia en España y América Latina: las reformas electorales (1880-1930). México: El Colegio de México, Fideicomiso Historia de las Américas, Fondo de Cultura Económica, 2000, pp. 208-229.

POTTER, Anne Louise. Political Institutions, Political Decay and the Argentine Crisis of 1930. Stanford: Stanford University, 1979.

REMMER, Karen. Party Competition in Argentina and Chile. Political Recruitment and Public Policy. 1890-1930. Lincoln: University of Nebraska, 1984.

ROCK, David. Politics in Argentina. 1890-1930. The Rise and Fall of Radicalismo. New York: Cambridge University Press, 1975.

ROJKIND, Inés. Orden, participación y conflictos. La política en Buenos Aires a fines del siglo XIX y comienzos del XX. Miradas clásicas y nuevas aproximaciones. Iberoamérica. América Latina-España-Portugal, n. 34, pp. 154-159, 2009.

ROMANO, Ruggiero; CARMAGNANI, Marcello. Componentes sociales. En: CARMAGNANI, Marcello; HERNÁNDEZ CHÁVEZ, Alicia; ROMANO, Ruggiero. Para una historia de América I. Las estructuras. México: El Colegio de México, Fideicomiso Historia de las Américas, Fondo de Cultura Económica, 1999, pp. 288-403. ROSANVALLÓN, Pierre. La consagración del ciudadano. Historia del sufragio universal en Francia. México: Instituto de Investigaciones Dr. José María Luis Mora, 1999.

SABATO, Hilda (coordinadora). Ciudadanía política y formación de las naciones. Perspectivas históricas de América Latina. México: El Colegio de México, Fideicomiso Historia de las Américas, Fondo de Cultura Económica, 1999.

SABATO, Hilda. La política en las calles. Entre el voto y la movilización. Buenos Aires, 1862-1880. Buenos Aires: Sudamericana, 1998.

SABATO, Hilda; LETTIERI, Alberto (compiladores). La vida política en la Argentina del siglo XIX. Armas, votos y voces. Buenos Aires: Fondo de Cultura Económica, 2003. SANCHEZ GOMEZ, Gonzalo. Ciudadanía sin democracia o con democracia virtual. A modo de conclusiones. En SÁBATO, Hilda (coordinadora). Ciudadanía política y formación de las naciones. Perspectivas históricas de América Latina. México: El Colegio de México, Fideicomiso Historia de las Américas, Fondo de Cultura Económica, 1999, pp. 431-444.

SARTORI, Giovanni. La influencia de los sistemas electorales. En: DUVERGER, Maurice; SARTORI, Giovanni. Los sistemas electorales. San José de Costa Rica: CAPEL, 1988, pp. 37-83.

Revista Eletrônica da ANPHLAC, n.14, p. 133-156, jan./jun. 2013. http://revista.anphlac.org.br/index.php/revista 
SMITH, Peter H. Argentina and the Failure of Democracy. Conflict among Political Elites. 1904-1955. Madison: The University of Wisconsin Press, 1974.

VARELA ORTEGA, José. Los amigos políticos. Partidos, elecciones y caciquismo en la Restauración (1875-1900). Madrid: Alianza Editorial, 1977.

VALENZUELA, Samuel. La ley electoral de 1890 y la democratización del régimen político chileno. En: MALAMUD, Carlos (coordinador). Legitimidad, representación y alternancia en España y América Latina: las reformas electorales (1880-1930). México: El Colegio de México, Fideicomiso Historia de las Américas, Fondo de Cultura Económica, 2000, pp. 130-161.

VIOTTI DA COSTA, Emilia. Brasil: de la monarquía a la república. México: Consejo Nacional para la cultura y las artes, 1995.

VON BEYME, Klaus. El origen de los sistemas de partidos. En: CALANCHINI URROZ, Juan (coord.). Cuadernos de Ciencia Política. Partidos políticos I. Montevideo: Fundación de Cultura Universitaria, Instituto de Ciencia Política, 1989, pp. 11-25.

WEBER, Max. Economía y sociedad, Volumen I. México: Fondo de Cultura Económica, 1944.

ZEITLIN, Maurice. The Civil Wars in Chile (or the Bourgeois Revolutinons that Never Were). Princeton: Princeton University Press, 1984.

ZUBILlaGA, Carlos. El difícil camino de la participación política. Población, ciudadanía y electorado. En: DEVOTO, Fernando; FERRARI, Marcela. La construcción de las democracias rioplatenses: proyectos institucionales y prácticas políticas. 1900-1930. Buenos Aires: Biblos, Universidad Nacional de Mar del Plata, 1994, pp. 31-68.

Recebido em: julho de 2012 e aprovado em: outubro de 2012.

Revista Eletrônica da ANPHLAC, n.14, p. 133-156, jan./jun. 2013.

http://revista.anphlac.org.br/index.php/revista 